April - 2003

\title{
Student Support in Open Learning: Sustaining the process
}

\author{
Christine Dearnley \\ University of Bradford \\ School of Health Studies \\ UK
}

\begin{abstract}
This paper discusses the aspect of student support that emerged as a key component of a longitudinal study into the experiences of nurses studying through open learning in the UK. Students engaged in this study were mature learners who were practicing nurses and predominantly, but not exclusively, women. Participants perceived entering higher education as a considerable challenge.
\end{abstract}

Keywords: longitudinal research; constant comparative analysis; social, professional and academic networks

\section{Student Support in Open Learning: Sustaining the Process}

During the two year nursing course, programme participants in this study were found to engage a range of strategies in order to access the support that they determined was necessary to sustain their academic undertakings. They adopted strategies within their social relationships to ease the practicalities of domestic requirements, and as a result, often re-evaluated such requirements in the light of new perspectives as the course progressed. For example, students developed strategies at work for sharing information, and for giving and receiving reassurance from colleagues and friends. They also turned to peers and tutors from their tutorial groups. This paper explores the strategies learners deployed and how these strategies help to sustain them in facing the challenges of change.

This paper aims to report the findings, in terms of student support, of a longitudinal study of the experiences of a group of enrolled nurses (ENs) studying on a two year open learning (OL) conversion course. This nursing programme was designed to "upgrade" original professional training and help nurses meet the increasing technological and academic demands of their profession.

Students enrolled in the course are placed within a tutor group of approximately fifteen students. Students may study a range of clinical specialities and have the option of attending group tutorials, two hours in duration each week during the term (thirty weeks a year). Course content is 
Dearnley Student Support in Open Learning: Sustaining the process

provided through paper based learning materials. Students are also entitled to individual tuition from the group tutor. To be eligible for enrolment in the programme, students must be working in clinical practice for at least twenty hours a week. Participants engaged in this study were predominantly women between the age of 37 and 50 years, and had between seven and 29 years experience in clinical practice prior to commencing the course. Generally, students' prior academic qualifications did not exceed General Certificate of Secondary Education (GCSE) level of study. They therefore represented a non-traditional student intake. As a result, students' prior experiences can inform the current agenda for widening participation in Higher Education (Kennedy 1997).

Study participants entered the programme demonstrating an array of emotions ranging from the fear that they might lack ability to "do the work," to excitement and delight at "being given an opportunity." Upon completion of the programme, participants engaged in this study where found to epitomize the ideals of lifelong learning: they experienced a range of personal and professional development characterized by changing ways of knowing (Belenky et al., 1986) and increased motivation for living and learning (Dearnley, 2002). As it is the aim of widening access to participation in higher education, the development of individuals with the skills of lifelong learning is a high priority on many current agendas in the UK and elsewhere (ENB 1994; Dearing 1998, DfEE 1998; DoH 1997; 1998; 1999; 2000a; 2000b; 2001; UNESCO 2000). This article aims to discuss the relationship between student support within the context of open learning, as well as the achievement of these aims.

\section{Background}

The history of the enrolled nurses (EN) and the requirement for them to convert professional qualifications from second to first level registration created the larger contextual conditions of the study. Previously registered nurses (RNs) trained for three years and are empowered to deliver nursing care within statutory limits (Brown, 1994). As such, RNs became known as "first level" registered nurses. By comparison, enrolled nurses (ENs) trained two years and hence their role, by statute, was to assist RNs. As a result, ENs became known as "second level” registered nurses. Despite the fact that they often performed similar duties when compared to RNs, who could become ward sisters, nursing managers, or enter specialties such as midwifery or health visiting, ENs, on the other hand, traditionally had few career options and even fewer opportunities for "topping up" their qualification to become RNs. The 1980s, however, saw a number of changes to the Health Service and nursing management, which resulted in ENs becoming an "oppressed" group of individuals. ENs were often de-valued on a professional level, and as a result, demotivated.

As has occurred in other countries, in 1987 the Project 2000 proposals (UKCC, 1987) were published in the UK announcing that EN training was to cease and there was to be a single level of registered nurse. It was at this juncture that ENs was offered the opportunity to convert to first level registration if they wished. This created considerable unrest and uncertainty among ENs, a group who at the time accounted for approximately one third of all nursing staff employed by the National Health Service (Dowswell et al., 1998). The demand for conversion courses, as they became known, was perhaps higher than had been anticipated and the open learning route provided the only feasible way for so many individuals to upgrade.

Participants in this open learning course were practicing as nurses and most had family and home commitments when they commenced the course. Few had any substantial academic qualifications or educational opportunities other then their original EN training and subsequent statutory 
Dearnley Student Support in Open Learning: Sustaining the process

updates. The need to respond to the demands of becoming an open learning student were thus to be in addition to their existing life responsibilities and events. Learners situated within this context thus required forms of support that were perhaps different from "traditional" students. Participants in this study demonstrated a range of strategies in which they engaged to access this support.

Nursing practice draws upon several ways of knowing (Berragan, 1998). Carper (1978) defined four patterns of knowing in nursing: empirical, ethical, aesthetic, and personal. Belenky et al. (1986) described different ways of knowing specifically related to women, and Perry (1970) constructed a scheme of knowledge development in college students, most of whom were men. The study drew upon these earlier works to explore the changing ways of knowing and nursing experienced by the participants. Belenky et al., (1986) identified several ways of knowing and implied that an individual moved from one position to another as a result of various experiences. Perry (1970) identified sequential positions, although he acknowledged, as did Belenky et al., (1986) that some individuals would choose to halt the process if the challenge of change became too great and that regression was possible. This paper elucidates the role of different support mechanisms in sustaining the challenge of change as the participants traversed from a professional epistemology of silence to one constructed through their own experience of caring.

\section{Methodology}

The study was undertaken within a phenomenological paradigm and was underpinned by a philosophy of participation and collaboration (Carr and Kemmis, 1986; McNiff, 1988; Hall 2001), reflecting ideals of post-modern feminist enquiry (Harding, 1987; Stanley and Wise, 1993; Maynard, 1994; Stanley, 1997; McGuire 2001). Data were collected through a total of 58 semistructured interviews, obtained from a bounded sample of eighteen participants, at five stages over the two year period of study. Supporting data were obtained from study skill inventories (Entwistle, 1983), distributed to a sample of 160 students studying the same programme at a number of higher education institutions at three stages throughout a two year period, as well as from researcher observations and reflections based on professional practice as an open learning tutor.

Analysis was undertaken through the processes of open, axial, and selective coding to identify the properties, conditions, and relationships between the emerging concepts and categories at each stage of data collection. In this manner, dense category formation and refinement were possible. This constant comparative method of data analysis was consistent with that suggested by Strauss and Corbin (1998).

Key concepts, along with their properties and dimensions, were identified and conceptually developed by the use of researcher memos and diagrams. Axial coding, whereby the analyst begins to fit the pieces of data together, was conducted conceptually and then in diagrammatic format. This method of analysis facilitated the development of "core categories" at each of the data collection stages. Categories that emerged in previous stages of the study were developed along various dimensions and along a six-month trajectory. Subsequently, core categories for each stage of the student experience emerged, whilst others, such as those entitled "the context of learning and development" and "learning to learn," were constant categories to which depth and vitality was added at each stage of the data collection and analysis process. In this manner, an over all model evolved (see Figure 1), dense category development was generated, and category relationships were explored. 
Check coding, (Miles and Huberman, 1994) whereby open coding was repeated on a number of transcripts and then categorized by means of conceptual axial coding, was repeated at each stage of the study. Another analytic strategy employed as a form of check coding was to discuss findings with the participants. This strategy was employed at the third and fifth stages of data collection and analysis and served to check assumptions and the emerging hypotheses by explaining to the respondents what the researcher was finding in the data. This strategy also provided an opportunity to ask participants whether the researcher's interpretation matched their experiences, and if not, then to identify the ways in which they were different (Strauss and Corbin, 1998; Maynard and Purvis, 1994; Badger, 2000). In this manner, the ethos of participation and collaboration within the study was increased. McNiff (1988) suggests that participants' reactions may be a researcher's strongest support in their claim to knowledge, whilst Maynard and Purvis (1994) discuss the problem of interpretation and how we know that we have interpreted the data as the participant would have wished. Returning to the participants, allowing them to read transcripts of their interviews and sharing the interpretations with them, enabled the researcher to check that the data had been interpreted in agreement with the participants, thus increasing the validity of the study.

The category entitled "context of learning and development," which emerged and was developed in terms of its properties and dimensions at each stage of the study, encompassed the important role of support in an open learning provision will now be discussed.

Figure 1. The Process of Development

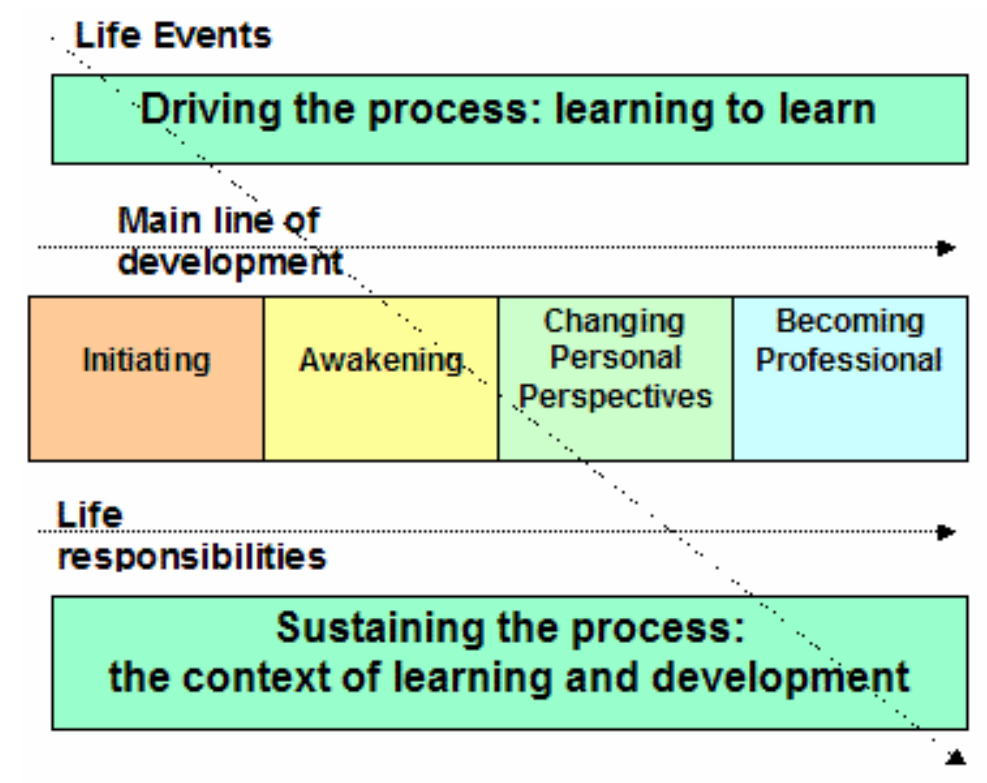

\section{The Context of Learning and Development: Sustaining the Process}

This was a major category in the study and was made up of three sub-categories: 1) professional roles and relationships; 2) social roles and relationships; and 3) academic roles and relationships. These sub-categories emerged at each stage of the data collection and analysis process. The objective was to identify any changes in these roles and relationships that impacted or were derived from the student experience and subsequent developments. In the final process of 
analysis and evaluation, the function of the category was identified as primarily that of sustaining the developmental process by the integration of three clearly defined supporting networks. These supporting networks were: 1) academic, consisting of tutors and peers; 2) professional, consisting of colleagues, managers and mentors; and 3) social, consisting of partners, children, extended families and friends.

Two key concepts permeating the study were "life responsibilities" and "life events." Life responsibilities represented all those social and professional roles and responsibilities likely to be ongoing throughout the duration of the course; they were felt to be constant and generally predictable. Life events, however, encompassed any number of unpredictable traumas and stressors that accompany adulthood, for example: bereavement, divorce, pregnancy, and new relationships. Whilst life responsibilities can be considered and catered for when planning adult learning curricula, life events may be expected and processes to accommodate such events as they occur, should be built into curriculum design. This is easier, to some extent, with open learning courses than with face-to-face courses, because students can break from their studies and return when they feel ready, rather than being governed by the availability of lectures that may have been missed. However, it is also acknowledged that student support is an important element in sustaining students through life events, whatever the mode of delivery.

Appropriate student support was seen to make the difference between student success and failure. Carnwell (2000) identified the importance of support in her study of nurses undertaking open learning programmes. She noted that this fell into three domains: 1) practical; 2) academic; and 3) emotional; these were mirrored in the current study. Students in this study identified the need for the following types of support:

- Practical support, for example with child care or domestic arrangements

- Technical support, for example how to word process

- Academic support in terms of writing skills, referencing, literature searching, etc.

- Emotional support, which was often just someone students could talk to about the pressures of being an adult learner

As mentioned previously, three main sources for this support were identified in the study as "social networks," "professional networks" and "academic networks." A further exploration of the three support systems will demonstrate the interplay between them, how when one system fails, another needs to be activated. Academic networks must be responsive to student needs. In order to achieve this, an awareness of social and professional networks and how they interact with academic networks, is required.

\section{Social Networks}

Daloz (1986) suggests that tutors of mature learners must recognise the social context in which learning takes place. In open and distance learning, this is of particular importance as it is in this context that most of the learning takes place. Social networks obviously vary in the form that they take, but interestingly, they seem to form the foundation of all support networks. Dearnley and Matthew (2000), Scott et al. (1998), and Asbee and Simpson (1998) each reported that "domestic harmony" is an essential ingredient in sustaining the motivation and ability for mature learners to continue studying. In the current study, it was noted that if all was not well at home, students found it difficult, if not impossible, to continue with their studies. Social networks generally provided the practical help that was required to enable students to set-aside the time necessary for effective study, and in many cases were the source of emotional support too. 
Dearnley Student Support in Open Learning: Sustaining the process

The causal conditions of this category of social networks relate to participants as adults with life responsibilities and commitments that required programme participants to adapt to a new role of student. Whilst there was pressure from within the profession for students to enroll in the programme for some time, there was an overarching theme: when they began the course, "the time was right" for this to happen, indicating that there was, in fact, and an element of personal choice in the decision to commence the course at a particular time. This choice was supported by such claims as: children were now old enough to be more independent and therefore less demanding on parental time, etc.

Pascall and Cox (1993) stated that the decision to return to education for women was frequently dependent upon "a complex web of circumstance being right," a finding that was mirrored in the first stage of the current study. Students chose to start the course at a particular time for a number of reasons, nearly all of which were based on social circumstances.

At early stages of the study, students discussed changes to their roles at home and how their families were coping. For example:

"Because I've got to get this work done. And I think, I think they've still got to get used to the idea that I'm not always gonna be there to do the washing and the ironing because I've got my head in a book and so there have changes been made..."

Some students discussed how their children had responded to them becoming a student. This varied from youngsters wanting to share the dining room table to do their "homework," to teenagers assuming responsibility for domestic chores. One student expressed her surprise that this support was forthcoming:

“[My] son does more, he does. (laughs) . . . He does . . He'll Hoover now, he [wouldn't] Hoover before ..... He'll dust and oh, he'll iron, he never used to iron and he will."

When asked what she thought had brought about these changes, she laughed again, and replied: "Because I haven't been able to do [them]."

It appeared, however, that in many cases, whilst support from various family members was offered initially, such support was often short lived. Later stages of the study revealed that most students either adopted Clouder's (1997) "must work harder” strategy, in that they added studying to their usual domestic responsibilities, or they re-evaluated the importance of domestic chores and relegated them in terms of their overall importance in life. For example, as one student said:

"Before, it used to worry me if I didn't do the ironing ... there could be a pile of ironing and I'd think, "I've got to get that ironing done before I can do anything else", but now it doesn't bother me, I can just, I can be quite blasé about it, cos there's more things to life than ironing or housework. And I feel that I try to fit in enjoying life more ... I think it's about prioritising my life and I know that ... I know that I've got to make time for studying now."

Whilst this student had successfully changed her domestic priorities and learnt to integrate studying with the rest of her life, supported by significant others, it must be noted that this was not an easy task and for some students, in that such changes in outlook created turbulence in their 
Dearnley Student Support in Open Learning: Sustaining the process

social roles and relationships. For these students, support was often needed from outside the domestic arena and many turned to their professional relationships for this support.

\section{Professional Networks}

Professional relationships and support had a strong effect on the students engaged in the study. In the early stages of the programme, support might have been as basic as being "allowed" to do the course, being funded, or being allocated time to study. Practical and emotional support was central to the part played by professional networks. If students worked in an environment that was not supportive, where they did not feel valued as learners, where study leave was withdrawn or reduced, they reported a negative impact in their approach to the programme and that their motivation for learning was severely jeopardised. Students who were less well supported at work, traversed through the process of development more slowly than did those who were well supported at work.

In terms of professional education, there is further evidence here to support the essential links between the practice area and the academic institution. In nurse education in the UK, links between the practice area and the academic institution are provided in a number of formal ways, such as link lecturers, who work between the academic institution and the clinical area, as well as mentor preparation workshops which were provided by the academic institution. However, this study has demonstrated that students rely most often on informal professional networks for vital practical and emotional support. One student explained how practical support at work made a difference to her:

"I've found, even four weeks into the course, that if you ask somebody something, they'll say, 'I've got one of those. Or I'll find you one of those. I'm sure I've got one of those, I'll photocopy it for you.'”'

However, there was also a place at work for emotional support, as she continued:

"At work everybody's been asking me how I'm getting on and, you know, all that sort of thing, that gives you a boost as well, you know."

Whilst formal systems frequently broke down, for example, when designated mentors or students moved practice areas, informal networks, which were frequently based on friendship or shared experiences, were stronger:

"Professionally, at work ... they're just behind me all the way, but they all do courses, they're all doing them, so they all understand a bit, you know."

Students relied on a complex web of emotional and practical support from within their social and professional networks. They sometimes turned to these networks for academic support too, such as retrieving materials, developing study skills, and technical support when using computers to search for resources or word-process their studies. For other aspects of study skills, such as interpreting learning materials, learning to become reflective and applying theory to practice, they turned to the academic networks, which will now be discussed. 


\section{Academic Networks}

Most participants in this study had no choice with respect to the method of course delivery. It was the only suitable course available locally and they were often "sent" on the course by their employers. Some had chosen to study by open learning modalities because of the flexibility it offered in terms of its delivery. However, whilst the flexibility often provides the opportunity to study, it may also prove problematic for some students. Many participants entered the course with preconceived ideas about their "needs" as learners. These "needs" were often based on earlier, sometimes negative schooling experiences. Such students frequently a felt need to be "told what to do and when to do it," behaviours which stem from earlier experiences that had encouraged dependency rather than autonomy in learning and an epistemology of received knowing (Belenky et al., 1986).

Earlier negative schooling experiences may also have contributed to participants' low levels of self-confidence in their ability to learn. Thus when tasked with identifying "their own learning needs" and planning "their own study time" around existing life responsibilities, the challenge for some individuals seemed insurmountable. For those who took up this challenge more comfortably, nonetheless tend to be defeated by the challenges of life itself, when life events intervened in the learning process.

Students in the study were returning to education after a period of many years and for most it was their first experience of higher education. Moreover, for most, it was their first open learning experience. Therefore, it is important to understand the emotional impact of returning to study as a mature learner. One student, just coming to terms with returning to study, explained that "the magnitude” was "beginning to dawn,” whilst another described the experience as "soul lifting.”

Many respondents reported having returned to studies in the epistemological position of received knowledge (Belenky et al., 1986). In this position, individuals tend to think of "authorities" as sources of truth. They depend on "authorities" to tell them what is right or wrong and believe that "authorities" hear words from even higher "authorities." Some participants began the course with this orientation. They believed that almost everybody in the professional hierarchy was "above them" in terms of "authority," and that professional knowledge passed down through that hierarchy to them. It is therefore likely that it was from this professional epistemology that students' anxiety and lack of confidence in their ability to learn evolved. It is also likely that other groups of mature learners will be returning to study with this epistemological orientation and will experience similar anxieties and emotions.

As learners, individuals with the orientation of received knowledge (Belenky et al., 1984) have distinct characteristics worthy of exploration within the context and demands of open learning. Students with this orientation tend to be intolerant of ambiguity, and to collect facts rather than to develop an opinion. In other words, such students either "get it" right away or don't "get it" at all. They usually make no attempt to understand or evaluate ideas. Thus these individuals tend to be surface learners, where material is to be stored in their heads and application of knowledge is difficult. Given that there was no "teacher" to tell these students what to do or what they needed "to get," the task faced by these learners to take responsibility for their own learning can be understood as enormous. No "authority" was going to tell them what to think, or when to think; they had to think for themselves. As they came to grips with open learning, the epistemological positions in which they had functioned for many years, in both their professional and social roles, was immediately challenged. 
Dearnley Student Support in Open Learning: Sustaining the process

These findings are supported by the results of the approaches to study inventories (Entwistle, 1983), which were distributed at the start of the course. Based on the analysis of 2208 students from a range of arts and science backgrounds, Entwistle (1983) offers mean scores and standard deviations as provisional norms. His mean score for reproducing orientations to study - i.e., surface learning, is 13.51 and the standard deviation is 4.40. Analysis of the returned questionnaires at the start of the current study indicated that the incidence of surface approaches to learning were high, with a mean score of 16.5 and a standard deviation of 4.09.

Responsive and flexible academic support was therefore required as students battled with the practicalities of returning to study, coming to grips with open learning, and issues such as "getting it down on paper," "references" and using the library. Crawford and Gorman (1995) found that using modern libraries was a concern for many adults returning to study, and this certainly seemed to be the case here as the students settled into the course. One student described the enormity of her experience in "cracking the library system:"

"But there's just something about this library downstairs, that it took me ages to walk through the door, and the first time I wanted to photocopy an article in a journal I went with me purse, and you know, me money, and that was another sort of, erm, erm . . . to, to, a step to actually get me card and to understand that. And I remember going home and telling my thirteen year old, nearly fourteen, saying, "Do you know what I did today." And she sort of looked at me as though, you know, "Wow, let's get giddy, Mum." You know ..."

Academic networks were divided into two distinct sets: 1) peers from the tutorial groups; and 2) personal tutors. The former were found to provide strong links from early in the course, and support from within these groups fell into the academic, practical, and emotional domains. Attending tutorials seemed to add to the academic experience, helping increase awareness of current thinking and, in so doing, motivating students to continue. This supports the findings of Gordon (1996), Stevenson and Sander (1998), and Bird (1999), who each found in their studies that group discussion was a popular teaching method that helped clarify issues and create opportunities for group interaction. Friendship, support, and trust were gained through group meetings and attendance at these, whilst not compulsory, was valued. Tutorial groups in the current study resembled Belenky et al.'s, (1986, p.118) “connected knowing groups,” which aided the transition to connected ways of knowing (Belenky et al., 1986).

One year into the course, one student noted that the group was "in fact, getting more, you know, interconnected at the moment." For almost all students, the tutorial groups were a fundamental aspect of support, and for many, provided a rich learning environment. The passage below demonstrates this:

"Our small group is really diverse and when we get together for the tutorials I think we cover an awful lot, and we get a lot from each other's personal experiences, or somebody else's view of a topic that we're covering out of the workbook. . . Somebody else will come with a completely different view of what they've been reading and I think, "This is wonderful," "I get a lot out of that."

Participants in the study discussed the role of the personal tutor at length. Good tutors were seen to provide support in any of the four domains: 1) academic; 2) emotional; 3) practical; and 4) technical. Primarily, tutors had to be approachable and accessible. In open learning, this is likely to have a variety of dimensions, particularly as email and Internet accessibility increasingly 
complement telephone or fax machine technology. But the type of access seemed less important to students in this study than actually knowing that support was available. In terms of emotional support, participants appeared to appreciate those tutors who encouraged and promoted confidence in their abilities to do the required work. In discussing the anxiety and stress that can be induced in learning situations generally, Newell (1992) suggested that whilst few teachers will have extensive training in cognitive-behavioural anxiety-reduction techniques, many nurse teachers already have transferable skills in stress reduction which can be called upon. These same skills are called upon frequently when working with adult learners who are returning to education after a considerable break and coping with life responsibilities and events simultaneously with their studies. One student summed up the supportive skills of her tutor in the following way

"I spoke to [my tutor] a few times who patiently listened and sort of, well, good counselling really."

Clearly, not all tutors will have "good counselling skills." However, the findings of this study indicate that there is a need, at minimum, to understand the issues, the context of learning, and a humanistic approach to student support.

\section{Reflection and Discussion}

Whilst it appears at face value that academic networks might be all that concerns those responsible for the delivery of open and distance learning, the study demonstrated that there is a considerable interplay between the three domains. Not all students will access all three systems; indeed, not all students will have access to all three. However, it appears important for each student to access at least one of these support systems.

Sound management of open learning delivery should aim to exploit the former virtues whilst minimizing the effects of the latter. This was of particular importance in the current study and the development of the academic and professional networks seems to have been successful in overcoming this issue.

The interplay between the systems was exemplified in the study by the case of one student who, just months into the course, was widowed and left with two young children. Professional networks came into play as working hours were offered that would enable this student to work whilst the children were at school. The academic network was activated and this student was supported by her peers in the tutorial group, not only emotionally, but also practically. Assignment submission dates were flexible and the open learning modality allowed the student to spend time away with her extended family. As one support system was lost, others took on more crucial roles and she was thus able to successfully complete the course.

Rogers (1996) highlights the growing awareness that "transfer of knowledge" models of adult education are ineffective, and act to encourage dependency and are thus inappropriate for the development of critical thinking. This study demonstrated how the processes of an open learning model of adult education proved effective in challenging existing ways of knowing, nursing, and being. Within the context of existing life responsibilities and with the intervention of life events, participants engaged, to varying degrees, with the learning process, took up the challenge of "doing their own thing," became reflective practitioners and developed the skills required for the delivery of evidence based care. In so doing, they changed the positions of both epistemology and motivation, from which they practiced as nurses. As they made this transition, each passed 
Dearnley Student Support in Open Learning: Sustaining the process

through recognisable stages (Figure 1). Participants, however, negotiated their own way through these stages and did so in their own time supported in their own unique ways.

Daloz (1986) suggests that when students receive an appropriate mix of challenge and support, development can occur. He asserts that when both support and challenge are low, little is likely to happen in terms of personal development. However, when support is enhanced, the potential for some form of personal growth is increased. On the other hand, too much challenge in the absence of appropriate support, can drive a student into "retreat, forcing a rigid epistemology to replace the promise of a more fluid and complex world" (Daloz, 1986, p. 215). It appears that in the current study, the open learning modality allowed students to assess the availability of support from social, professional and academic networks and, in most cases, create an environment that provided an appropriate mix of both challenge and support.

\section{Implications for the Delivery of Open and Distance Learning}

A number of key issues emerged in this study that have implications for the successful provision of open and distance learning. These will now be discussed.

The initial lack of confidence in their ability to develop learning skills that was reported by participants is likely to be found in other groups of mature open learners. Indeed, it is reported by Pascall and Cox (1993), Crawford and Gorman (1995), Gordon (1996) and Bird (1999), that student support is a key role in any learning environment. However, the findings of this study indicate that the role of the open learning tutor is perhaps as multifaceted as open learning itself. Tutors' skills in offering student support are not only vital, but also unique. This is largely because open learning tutors are usually supportive, and adult learners have a wide range of needs that are different to the average school leaver entering higher education (Knowles 1990; Rogers, 1993). It is also because the flexibility that attracts adults to open learning may also contribute to their downfall. Many new skills have to be learnt by adults returning to higher education via the open learning modality, these include time management and technological skills in addition to the expected academic attainment. Learning new skills can be daunting and traumatic if experienced alone. Regular contact, therefore, becomes imperative and contact agreements should be arranged early in the student/ tutor relationship. Conflict can occur if tutors expect student autonomy too early in the course trajectory; failure to make contact does not necessarily mean that all is well with the student; it may simply mean that they haven yet to develop sufficient confidence to accept responsibility for initiating that contact.

It is in the recognition of these unique needs, and the ability to respond appropriately, that the foundations of a high quality open learning provision lie. Students must be recognised as adults with life responsibilities who are prone to life events. Support structures to facilitate personal and professional development within this context need to be in place and attention must be given to the provision of effective learner support. There must liaison between academic, professional and social networks. Stevenson and Sander (1998) suggest that given their importance for positive student outcomes, efforts to capitalise on students' relationships with family and friends must be made. With this is mind, the University of Bradford developed an introductory leaflet for families to be distributed to new open and distance learning students. Similarly, Paul (1990) suggests that in recognition of the essential support that is inherent in peer relationships, institutions offering open and distance learning have a responsibility to do whatever they can to put students in contact with each other. Tutors play a central role in orchestrating these various elements in order to provide a supportive learning environment that will enable students either to pursue their studies to a successful outcome, or to make an informed decision to defer or discontinue registration. 
Finally, as open and distance learning expands to permeate into the realm of e-learning, the findings of this study suggest that a major challenge will be to develop electronic forms of "connected knowing groups" in order to support students and sustain their motivation for learning and development.

This paper has discussed the findings of a recent investigation into open learning and their impact on personal and professional development. Primarily, the paper has elucidated the aspect of student support and the crucial role that it played, in its varying forms, in sustaining the process of learning and development among the participants of the investigation. Although open learning is a multifaceted concept, the essential element of student support is likely to be a constant necessity to be integrated in all open learning curricula, regardless of delivery system. There is a current drive to increase the quality of higher education provision, coupled with increasingly flexible modes of delivery and the nurturing of lifelong learners (ENB, 1994; Dearing, 1998; DfEE 1998; DoH, 1997; 1998; 1999; 2000a; 2000b; 2001; UNESCO, 2000). Increased understanding and awareness of the relationship between student support and learning and development can play a crucial role in achieving these objectives.

\section{References}

Asbee, S., and Simpson, O. (1998). Partners, Families and Friends: Student Support of the Closest Kind. Open Learning 13(3),53 - 59.

Badger, T. G. (2000). Action research, change and methodological rigour. Journal of Nursing Management 8(7), $201-207$

Belenky, M. F., Clinchy, B. A., Goldberger, N. R., and Tarule, J. M. (1986). Women's ways of Knowing. New York: Basic Books.

Berragan, E. (1998). Nursing practice draws upon several different ways of knowing. Journal of Clinical Nursing 7(3), 209 - 217.

Bird, E. (1999). Lifelines and Life Lines: re-training for women returning to higher level occupations - policy and practice in the UK. International Journal of Lifelong Education 18(3), 203-216.

Brown G., (1994). Enrolled Nurses: Where do they go from here? Journal of Nursing Management 2, 213 - 216.

Carnwell R., (2000). Approaches to study and their impact on the need for support and guidance in distance learning. Open Learning 15(2), $123-140$.

Carper, B. (1978). Fundamental ways of knowing in nursing. Advances in Nursing Science 1(1), $13-23$.

Carr, W., and Kemmis, S. (1986). Becoming Critical: Education, knowledge and action research. London: The Falmer Press.

Clouder, L. (1997). Women's Ways of Coping with Continuing Education. Adults Learning 7(6), $146-148$. 
Crawford, W., and Gorman, M. (1995). Future Libraries, Dreams, Madness and Realities. Chicago: The American Libraries Association.

Daloz, L. A. (1986). Effective Teaching and Mentoring: Realizing the transformational power of adult learning experiences. San Francisco: Jossey Bass.

Dearing, R. (1997). National Committee of Enquiry into Higher Education. Higher Education in the Learning Society, Report of the National Committee. Norwich, UK.: HMSO.

Dearnley, C. A., and Matthew, R. G. S. (2000). A Group of Nurses Experience Open Learning: Exploring the Impact. Open Learning, 15(2), 191 - 206.

Dearnley, C. A. (2002). Finding the Professional Voice: a study of enrolled nurses converting to First Level Registration through open learning. PhD Thesis. University of Bradford, UK.

DfEE (1998). The Learning Age website. Retrieved September 2000 from. http://www.lifelonglearning.co.uk/greenpaper/ch0000.htm

DoH (1997). The New NHS: Modern Dependable. London: The Stationery Office.

DoH (1998). A First Class Service: Quality in the New NHS. London: The Stationery Office.

DoH (1999). Making a Difference - Strengthening the Nursing, Midwifery and Health Visiting Contribution to Health Care. London: The Stationery Office.

DoH (2000a). Continuing Professional Development: Quality in the New NHS. London: The Stationery Office.

DoH (2000b). The NHS Plan: A plan for investment, a plan for reform. London: The Stationery Office.

DoH (2001). Working Together - Learning Together: A Framework for lifelong learning for the NHS. London: The Stationery Office.

Dowswell, T., Hewison, J., and Millar, B. (1998). Enrolled Nurse Conversion: Trapped into training. Journal of Advanced Nursing 28(3), 540 - 547.

ENB (1994). Creating Lifelong Learners: Partnerships for care. Luton, UK.: Chilton Press.

Entwistle, N. (1983). Styles of Learning and Teaching. Chichester, UK.: John Wiley and Sons.

Gordon, M. (1996). New Horizons 20 Years On. Occasional Papers Series: No7.: University of Edinburgh.

Hall, B. L. (2001). I Wish This Were A Poem Of Practices Of Participatory Research. In P. Reason and H. Bradbury (Eds.) Handbook of Action Research, Participative Inquiry and Practice. London: Sage.

Harding, S. (1987). Feminism and Methodology. Milton Keynes, UK.: Open University Press. 
Kennedy, H. (1997). Learning Works: Widening participation in further education. Coventry, UK.:The Further Education Funding Council.

Knowles, M. S. (1990). The Adult Learner: A neglected species. Houston, TX.: Gulf.

Maynard, M. (1994). Methods, Practice and Epistemology: The Debate about Feminism and Research. In Maynard M., Purvis J. (Eds.) Researching Women's Lives from a Feminist Perspective. London: Taylor and Francis.

Maynard, M., and Purvis, J. (1994). Researching Women's Lives from a Feminist Perspective. London: Taylor and Francis.

McGuire, P. (2001). Uneven Ground: Feminisms and action research. In P. Reason and H. Bradbury (Ed.) Handbook of Action Research, Participative Inquiry and Practice. London: Sage.

McNiff, J., (1988). Action Research: Principles and practice. London: Macmillan.

Miles, M. B., and Huberman, A. M. (1994). Qualitative Data Analysis. London: Sage.

Newell, R. (1992). Anxiety, accuracy and reflection: the limits of professional development. Journal of Advanced Nursing, 17, 1326 - 1333.

Pascall, G. and Cox, R. (1993). Women Returning to Higher Education. Buckingham, UK: Open University Press.

Paul, R. (1990). Towards a new Measure of Success: Developing independent learners. Open Learning, 5(1), 31 - 38.

Perry, W. (1970). Forms of Intellectual and Academic Developments in the College Years. New York: Holt.

Rogers, A. (1993). Adult Learning Maps and the Teaching Process. Studies in the Education of Adults, 22(2), 199 - 220.

Rogers, A. (1996). Teaching Adults. Milton Keynes, UK.: Open University Press.

Rogers, C. (1983). Freedom to Learn for the Eighties. Ohio: Charles Merrill.

Royal College of Nursing (1998). Clinical Guidelines: What you need to know. London: RCN.

Scott, C., Burns, A., and Cooney, G. (1992). Motives For Return To Study: Mature age women. International Journal of Career Development, 4, 32 - 39.

Stanley, E., and Wise, S. (1993). Breaking Out Again: Feminist ontology and epistemology. London, Routledge.

Stanley, E. (1997). (Ed.) Knowing Feminisms. London: Sage. 
Strauss, A., and Corbin, J. (1998). Basics of Qualitative Research. Second Edition. London: Sage.

Stevenson, K., and Sander, P. (1998). How Do Open University Students Expect to be Taught at Tutorials? Open Learning, 13(2), 42 - 46.

United Kingdom Central Council (1987). Project 2000, Project Paper 9, The Final Proposals. London: UKCC.

United Nations Education, Scientific and Cultural Organization (UNESCO) (2000). Europe and North America redefine basic education for the information society. UNESCO Press. Retrieved May 5, 2003 from: http://www.unesco.org/bpi/eng/unescopress/2000/00$\underline{\text { 09e.shtml }}$

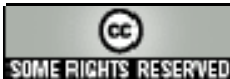

